\title{
The short but interesting life of small software firms
}

\author{
Mario Raffa, Giuseppe Zollo, Renata Caponi \\ ODISSEO-DIS, Dept. of Computer Science \& Systems, University of \\ Naples "Federico II" \\ Via Diocleziano 328, 80124 Naples, Italy, phone: +39815704498 , \\ fax:+39815704498,e-mail: zollo@nadis.dis.unina.it
}

\begin{abstract}
The paper analyses the organizational transformations of small innovative firms and the influence of the entrepreneurial know how on the growth path of the firms. A sample of 32 software firms has been investigated for more than fifteen years by the research group. From the raw data the authors derived 103 different organizational profiles, resulting in seven configurations. The results of the research show complex growth paths. Most of firms are not able to sustain a competition, mainly based on technological innovation. While the firms based on an initial technical know-how shows a variety of trajectories, the firms based on an initial orientation to market are forced to renounce to the software development as the main business. Most of the surveyed firms stop to exist as small software firms. For most of them their life as software producers lasted from three to seven years.
\end{abstract}

\section{Keywords}

Entrepreneurial know-how, growth path, organizational configurations

\section{THE KNOW-HOW OF ENTREPRENEURIAL FIRMS}

Start-ups are common in emerging industries, such as personal computers, software, industrial control, biotechnology, and so on. Those sectors are interested by the presence of many competing and often redundant companies, created under the double pressure of availability of resources and growing market demand. A wide range of strategic and organizational choices are available for those firms, because traditions, habits, culture, standard process technology and reference examples are quite completely absent (Kao, 1991). In such conditions the organizations must deal with a high degree of uncertainty both internally and externally. The original culture, vision, skills of the entrepreneur is the unique factor which can turn the original ambiguity, uncertainty and disorder into a successful organization (Filion, 1991). 
Increasing number of studies refer to the personal characteristics of entrepreneur the success of the firm in the early stages of its life (Miller et al. 1988; Lefebvre and Lefebvre, 1992). Roberts (1991) presents a schematic model which assumes that new companies are dependent at their formation upon the technological base learned by the entrepreneur from the incubating source, i.e. former companies, university laboratories, engineering departments. Personal abilities and individual attitudes are seen to be critical factor of successful entrepreneurial technology transfer.

This does not imply that the firm's performances should be attributed to the entrepreneurial characteristics alone. During the passage from organizational infancy to adulthood the firm undergoes the crises of control and directions (Greiner, 1972), due to the necessity to reduce the central role of the entrepreneur. After the first critical event, the firm's innovative abilities are based on a complex range of interacting factors (Acs and Audretsch, 1990; Rothwell, 1988; Pavitt, 1988; Storey and Johnson, 1987; Gibb and Scott, 1985; Kelly and Brooks, 1991):

a) structural incentives to innovate;

b) internal technological resources;

c) resources of the network within which the firm is included.

The literature shows the picture of a small growing firm that, for supporting successfully its innovation capability, must have a minimum size, hold internal skills, maintain a network of stable linkages with external economic agents.

The in-firm/out-firm relationships are crucial to support small firms' innovation capabilities in the growth stage. This is due to two reasons: a) the small firms' difficulty to finance longterm internal technological developments (Greiner, 1972; Huppert, 1981; La Belle et al., $1980)$; b) the difficulty of sustaining their technological capabilities when loosing the inventor-founder-manager's support increasingly concerned with the firm management (Meyer and Roberts, 1986).

Summing up the current knowledge, the founder-entrepreneur plays a crucial role during the first stage of firm's life, while, during the growth stage a more complex set of resources is necessary to sustain the firm's activities. According to Roberts (1991), fewer articles focus upon detailed aspects of technical base of new firms during the both stages. It has been developed a detailed analysis on small software firms, including several case-studies, in order to point out the evolution of firms founded by entrepreneurs with strong scientific and technical background.

Software small firms were chosen for two reasons:

a) in the software industry manufacturing technology is basically made up of technicianembodied professional skills. In spite of the remarkable development of the software engineering in the last ten years, and notwithstanding the early availability of advanced development environments such as the CASE, professional skills will still be crucial in the next years. For this reason software firms are an excellent laboratory to analyze the organizational implications of person-embodied technologies;

b) in the last decade the small firm was really prevailing in the industry development. However the competitive situation is changing due to the higher focus by traditional information technology leaders (hardware producers) on software manufacturing. This, together with the strong technological dynamics and the new demand characteristics, is rapidly changing the small firms' room of maneuver. 


\section{THE ENTREPRENEURIAL KNOW-HOW IN SOFTWARE FIRMS}

Software production is characterized by applied know-how (Werner, 1983; OECD, 1982, 1986). The know-how is, however, very complex to be acquired and it often requires the contribution of technical entrepreneur and a large number of skilled personnel (Weinberg, 1982). Applied know-how is basically made of three elements (Raffa and Zollo, 1988): 1) basic technology visibility, i.e. the knowledge of the performance of the basic products and their full use; 2) different technologies integration capacity, i.e. technical ability not related only to a given sector but to a wide range of disciplines, so that a complex system can be made; 3) market visibility, i.e. the capability of following demand trends and market opportunities opened up by applied technologies.

In order to understand how this know-how is formed and developed it is necessary to refer to the know-how of the neighboring sectors, i.e. those sectors where entrepreneurs come from. Within these neighboring sectors four types of know-how can be detected: basic knowhow (group 1), which includes scientific and technological skills forming the nucleus of the sector technologies. These skills are learnt in various places such as universities, research centres, large information technology and electronics firms, large EDP user firms, all of which are characterized by their specific and complex technological development. Know-how of related goods (alternative and complementary goods) (group 2), which consists of a deep knowledge of the customer needs (business consultancy, EDP consultancy), of the firms' software problems (information services, hardware producers). Market know-how (group 3), which consists of a knowledge of the demand trends and characteristics and of the marketing channels (hardware and software sellers). User know-how (group 4), i.e. the knowledge required to introduce the software products into existing organizations. This know-how starts from a detailed knowledge of the user needs (a firm, a production department, a class of business) so as to define the software product's characteristics, and, hence, to attempt the switch to software production, firstly to serve the captive market and then the open market.

Given the articulated nature of software technology, the software industry growth can be seen as a colonization of the adjacent sectors through a widening of their technological horizons (Mintzberg, 1985, 1987; Rothwell and Zegveld, 1982).

\section{THE SAMPLE}

The outcomings illustrated in this paper are grounded on a fifteen years research starting from 1979. During the years $1983-84,132$ software firms were studied, representing $84 \%$ of the software firms in Southern Italy, the less developed area of the country. The core of the software industry in Southern Italy was made up of small firms: $58.27 \%$ of the sample have less than 10 employees, and $21.26 \%$ have between 11 and 20 employees, while only $4.72 \%$ have more than 100 employees. The medium-sized firm range is very narrow in this sector (15.75\%). For many of those firms detailed case studies are developed, and several firms are analyzed in different stages of their life. In the years 1989-90 and 1993-94 new field surveys was carried out regarding small firms out of the firms sample studied in the years 1983-84. The new survey was aimed at analyzing organizational changes, development paths, product strategies and firms' performances. It was difficult to contact every single firm studied in the first survey: some of them ended up their activities, some changed location and address, 
others changed their name. At present, 80 firms are studied. However the investigated sample is sufficiently meaningful and some considerations can be made as to the relation between initial know-how and firm development. A large number of indications emerged from the research, but the present paper summarizes only the outcomes related to 32 small firms, which are considered a typical example of how the original culture of the entrepreneur affected the growth path of the firms.

\section{THE FIRMS' FORMATION}

In Italy the software sector began to develop from 1979 onwards. More than $70 \%$ of the firms operating in ' 84 first appeared between ' 79 and ' 84 . Firms established before this date carried out related activities such as data processing for third parties and hardware sales, and some of them later on diversified into software production. It is important to stress at this point that most of the small software firms do not produce only software, but have a mixed output.

\subsection{The entrepreneurial know-how}

In order to analyze differences in the initial know-how during the establishment stage, references is made to the three initial development stages of the Italian software industry: incubation (up to 1978), takeoff (1979-80) and growth consolidation (1981-84) (Table 1). The development of the software sector is closely bound to the acquisition of its know-how. The research revealed that $34.4 \%$ out of 132 firms entered the sector with basic know-how (group 1). This know-how is basically held by technicians who have left large firms operating in the information technology and electronics sector, or having a university background. Basic know-how was conspicuous in the three periods analyzed, and it played a particularly important role in the sector take-off period (1979-80), where it was responsible for the establishment of $40 \%$ of the firms.

Table $1 \%$ of firms according to the know-how of their establishment or of their diversification into software sector

\begin{tabular}{lcccc}
\hline \multirow{2}{*}{$\begin{array}{l}\text { Neighboring } \\
\text { know-how sectors }\end{array}$} & \multicolumn{3}{c}{$\begin{array}{c}\text { Period of } \\
\text { establishment/diversification }\end{array}$} & \multirow{2}{*}{ Total } \\
\cline { 2 - 4 } & up to 1978 & 1979 -'80 & 1981-'84 & of firms \\
\hline Basic know-how sector (group 1) & 25.71 & 40.00 & 36.36 & 34.40 \\
Related goods know-how (group 2) & 25.71 & 22.86 & 16.36 & 20.80 \\
Market know-how (group 3) & 20.00 & 22.86 & 30.92 & 25.60 \\
User know-how sector (group 4) & 28.58 & 14.28 & 16.36 & 19.20 \\
Total & 100.00 & 100.00 & 100.00 & 100.00 \\
\hline
\end{tabular}


A given share of the firms (19.20\%) entered the software sector with user know-how (group 4). It is important to note how this know-how was crucial in the sector's first period of incubation (in $28.58 \%$ of the firms), while its role declined in the following periods. This was due to the fact that users started producing software by themselves because of inability or nonexistence of supply to meet user needs. Consequently the know-how, acquired for internal production, was then utilized for the market. In the subsequent periods the appearance of an adequate supply reduced the need for self developed software. Finally, $46.40 \%$ of the firms entered the software sector with users' needs and market know-how, which can be divided into two large groups (groups 2 and 3 of Table 1). The group 2 includes competencies on software applications and information technology (organizational consultancy, EDP consultancy, services firms, hardware assembly) and represents $20.80 \%$ of the firms. The group 3 concerns the knowledge of demand characteristics as a result of the activities carried on (software and hardware selling) and accounts for $25.60 \%$ of the firms. The role of this know-how increases as the market develops.

\section{ORGANIZATIONAL TRANSFORMATIONS IN SMALL INNOVATIVE FIRMS}

The life of the small innovative firms is marked by changes that can give rise to different outcomes, such as growth, survival, or death (Raffa and Zollo, 1994). In any case the small innovative firms have to cope with external changes (competitors, market, technology) and internal changes (professional skills, organization, management). Several field researches performed in the United States, in Great Britain and in Italy, highlighted that, while in the mature industries, many firms do not experience any growth, in the innovative industries the small firms have many options. The high development rate of those industries drives the small firm to focus its attention on growth issues. This in order to follow the market expansion, to have access to new market segments and, ultimately, to acquire market and technological skills through the collaboration with other firms or the acquisition of new firms.

\subsection{The original know-how and firm's transformations}

The life of the small innovative firms is usually typified by a technology-oriented stage and by a marketing-oriented stage (Greiner, 1972; Brandt, 1981). The technology-oriented stage is characterized by an internal focus: the firm develops its key technologies and identifies its strengths and weaknesses. In the marketing-oriented stage the firm focuses its attention on the market and on formal management and planning methods. The organizational and managerial crisis experienced when shifting from the first to the second stage gives rise to a distinction between management and development functions and to a leading group in which different skills are combined (Kao, 1991).

While in the large firm most of the uncertainties are overcome through full and visible changes in the organization pattern (creation of new firm functions, new responsibilities, new hierarchies, new communication lines) (Kay, 1984), in the small firm (where the organizational pattern is less structured) most of the uncertainties are overcome through responsibility changes, differentiation and rearrangements of the firm's activities. The new relations amongst the firm's subjects are heuristically experimented through a set of trials for new 
development paths. In this context - typified by a high uncertainty typical of innovative industries - targets and tools for their achievement are ambiguously perceived. Moreover, given the limited rationality of the firm's actors, the missing information is supplemented by individual creativity. For this reason small innovative firms can give rise to different development paths, even though they have similar internal requirements and operate within the same competitive environment.

The entrepreneur's technical role is crucial for the firms' development. Several empirical studies has demonstrated that in small firms technological entrepreneurs play a central role to influence the successful technological innovations and firm's strategies (Miller and Toulouse, 1986a, 1986b; Roberts, 1991). Entrepreneur's characteristics, such as professional and technical background, are considered the most important resource associated with the ability of the firm to innovate and to growth (Roberts, 1991). On the other side, several authors report situations where the entrepreneur blocks the growth potentiality of small firm (Meyer and Goes, 1987). The ambivalence concerning the role of the entrepreneur seems to be related to the fact that the firm goes through various organizational stages during its growth process (Churchill and Lewis, 1983; Kimberley and Miles, 1980). At each stage a particular combination of resources is requested in order to success.

A sample of 32 software firms has been investigated for more than fifteen years, and the research group collected several questionnaires and case studies for each firm. The field data have been analyzed in the light of configurational theory (Meyer et al., 1993), resource-based theory (Grant, 1991; Prahalad and Hamel, 1990), and growth-stage theory (Greiner, 1972; Kimberly and Miles, 1980). The growth process of the firm has been considered as a change process and the life of the firm as a sequence of developmental stages. A organizational profile corresponds to every stage. From the raw data 103 different organizational profiles have been derived. Each profile was defined by the values assumed by a set of resources. The set of resources was gathered from literature of small innovative firms (Reid and Jacobsen, 1988; Kelley and Brooks, 1991; Quinn, 1979; Garden, 1992), and from the literature on software firms (Barocci et al., 1983). A set of 16 resources were identified, grouped in three subsets:

i) resources related to the entrepreneurs (individual know how, experience, personal network, involvement in software development). These resources concern the background experience of the entrepreneurial group and the involvement of the entrepreneurs in the technical and managerial aspects of the firm;

ii) resources related to professionals (technical abilities, professional skills, variety of competencies). These resources concern the competencies of the professionals of the software firms. The level and the diversification of competencies are very important to sustain the competitiveness of the small firm;

iii) resources related to the organization and technology (firm size, cooperation with external subjects, internal methodologies). These resources concern the technical and market experience of the firm, that is the presence of organizational routines, technology, structured relationships with the environment.

\section{MAIN CONFIGURATIONS}

On the basis of the variables identified as resources, 103 organizational profiles have been identified. The close analysis of the profiles led to the definition of seven organizational 
configurations. The configurations were derived through the identification of a small subset of resources influencing each other and forming a self-supporting cycle of relationships. For example, the high technical competencies of the entrepreneur influences positively the level of involvement of the entrepreneur in software development activities. The resulting focus on technical problems influences the prevalent competencies of the employees, who are technicians. The development group is dominated by the entrepreneur, and the technical information come from the entrepreneurial personal network. These stable and mutual reinforcing relationships are the core of the configurations. According to the configurational approach, a configuration is established when each resource acts as catalyst to reproduce the others. The identified configurations are the followings:

$\mathrm{Cl}$ Configuration based on technical know how of entrepreneurial group (\# of configurational profiles: 17). The entrepreneur is a technician coming from other firms or from university. He dedicates attention and time almost exclusively to product development. The non-technical competencies are poor, while organizational structure of development group is informal. The firm is constituted by one or more software project groups.

C2 Configuration based on professionals (\# of organizational profiles: 13). This configuration is characterized by new competencies, both technical and marketing, and by collaborations with external consultants and professionals, who have a part-time relationships with the firm.

C3 Configuration based on network (collaborations with larger firms, sw and services firms, technical environment and university) (\# of organizational profiles: 18). The competitive capability of the firm is based on relationships with other external subjects, particularly large hardware firms. These relationships allow the small firm to acquire new managerial and market skills, that integrate initial technical abilities.

C4 Configuration based on organizational routines and development methodologies (\# of organizational profiles: 8). This configuration marks the shifting from an organizational structure focused on entrepreneur to a structure regulated by a set of procedures and standard, for both development and managerial activities.

C5 Configuration based on market relationships (\# of organizational profiles: 14). The competitive capability is based on entrepreneurial market knowledge, that allows the firm to response rapidly to needs of the market.

C6 Configuration based on integrated and specialized products/services (\# of organizational profiles: 9). Firm's competitiveness is based on firm's capability to response to needs of market supplying complementary services to the basic product. Collaborations with customers are generally limited to local market. This configuration is also characterized by new competencies market oriented.

C7 Configuration based on systems' commercialization (\# of organizational profiles: 24). This configuration is characterized by several activities: hardware and software commercialization, training activities, organizational consultancy. Generally, software development is only a support to the other activities.

\section{FIRMS' EVOLUTION}

The growth path of firms could be considered a sequence of moves from one configuration to another. At their beginning firms have two possible configurations: $\mathrm{Cl}$, based on technical 
entrepreneurial know-how, and C5, based on market entrepreneurial know-how. Consequently, firms are polarized on technology or on market. Among analyzed firms, 17 belong to first group ( $\mathrm{Cl}$ configuration based on technical know how of entrepreneurial group), and 15 to second group (C5 configuration based on market competence of the entrepreneur). Both those firms' groups have to complete their initial know how to develop their activities. Consequently each firm after few years modifies its initial organizational configuration.

\subsection{The growth path of the firms based on technical entrepreneurial know-how}

The 17 firms based on technical entrepreneurial know how ( $\mathrm{C} 1$ configuration) have to complete their capability by expanding market competencies. The pattern of growth shows very diversified paths, which indicates the necessity for the firms to explore a variety of opportunities. It is very important to underline that this initial variety at the end converges to a small number of organizational solutions.

This occurs through different ways:

i) relationships with other firms, which determine the passage from $\mathrm{C} 1$ configuration (technical-firms) to $\mathrm{C} 3$ configuration (network-firms);

ii) collaborations with professionals and consultants, which determine the passage from $\mathrm{C} 1$ configuration (technical-firms) to $\mathrm{C} 2$ configuration (professional-based firms);

iii) new market abilities realized by a diversification of entrepreneur activities or by new employees market oriented. Those firms, generally, are focused on local market and develop strong relationships with their clients. Close collaborations with customers allow the firms to develop several services around their basic software products. This fact determines the passage from $\mathrm{Cl}$ configuration (technical-firms) to $\mathrm{C} 6$ configuration (services-orientated firms);

iv) organizational structure regulated by a set of procedure and standards, for both development and managerial activities, which determine the passage from $\mathrm{Cl}$ configuration (technical-firms) to $\mathrm{C} 4$ configuration (procedures-based firms);

v) finally, some firms strongly modify their initial vocation, increasing market competencies and focusing on hardware and software commercialization. This fact determines the passage from $\mathrm{C} 1$ configuration (technical-firms) to $\mathrm{C} 7$ configuration (commercialization-based firms).

These passages from $\mathrm{Cl}$ configuration to other configurations can occur directly, or through other intermediate configurations. From a statistical point of view we can observe that the most important paths that the firms follow are those depicted in Figure 1.

We have that $24 \%$ of the firms starting with $\mathrm{C} 1$ configuration pass to the $\mathrm{C} 2$ configuration, and successively to $C 4$ configuration (12\%) and to C7 configuration (12\%); while the $29 \%$ to C3 configuration and successively to $\mathrm{C} 7$ configuration. The others pass strictly to C6 configuration (12\%) or to $\mathrm{C} 7$ configuration (23\%); only one remain in $\mathrm{C} 1$ configuration $(6 \%)$ and only one passes directly to $\mathrm{C} 4$ configuration (6\%). With reference to Figure 1 , the passage from $\mathrm{C} 1$ initial configuration (technical-firms) to $\mathrm{C} 4$ configuration (procedures-based firms) determines an organizational transformation involving both technological resources (technical standards adoption) and organizational resources (engagement of new employees). 
Since these resources become internal firm's resources we say that the passage from $\mathrm{C} 1$ configuration (technical-firms) to $\mathrm{C} 4$ configuration (procedures-based firms) is characterized by an internalization strategy of technological and organizational resources.

The passage from $\mathrm{C} 1$ configuration (technical-firms) to $\mathrm{C} 2$ configuration (professionalbased firms) is mainly characterized by a product diversification strategy and by a strategy of complex networking with professional resources (new technical competencies acquisition), with different degrees of membership in the firm. Instead, the passage from $\mathrm{Cl}$ configuration (technical-firms) to $\mathrm{C} 6$ configuration (services-orientated firms), is mainly characterized by a networking strategy (collaborations with customers) and by a vertical market strategy, while the passage from $\mathrm{C} 1$ configuration (technical-firms) to $\mathrm{C} 3$ configuration (network-based firms) is characterized by a networking strategy (concessionaire of large hardware firm, jobbing, leveraged buy-out by large firms, collaborations with other firms to develop package).

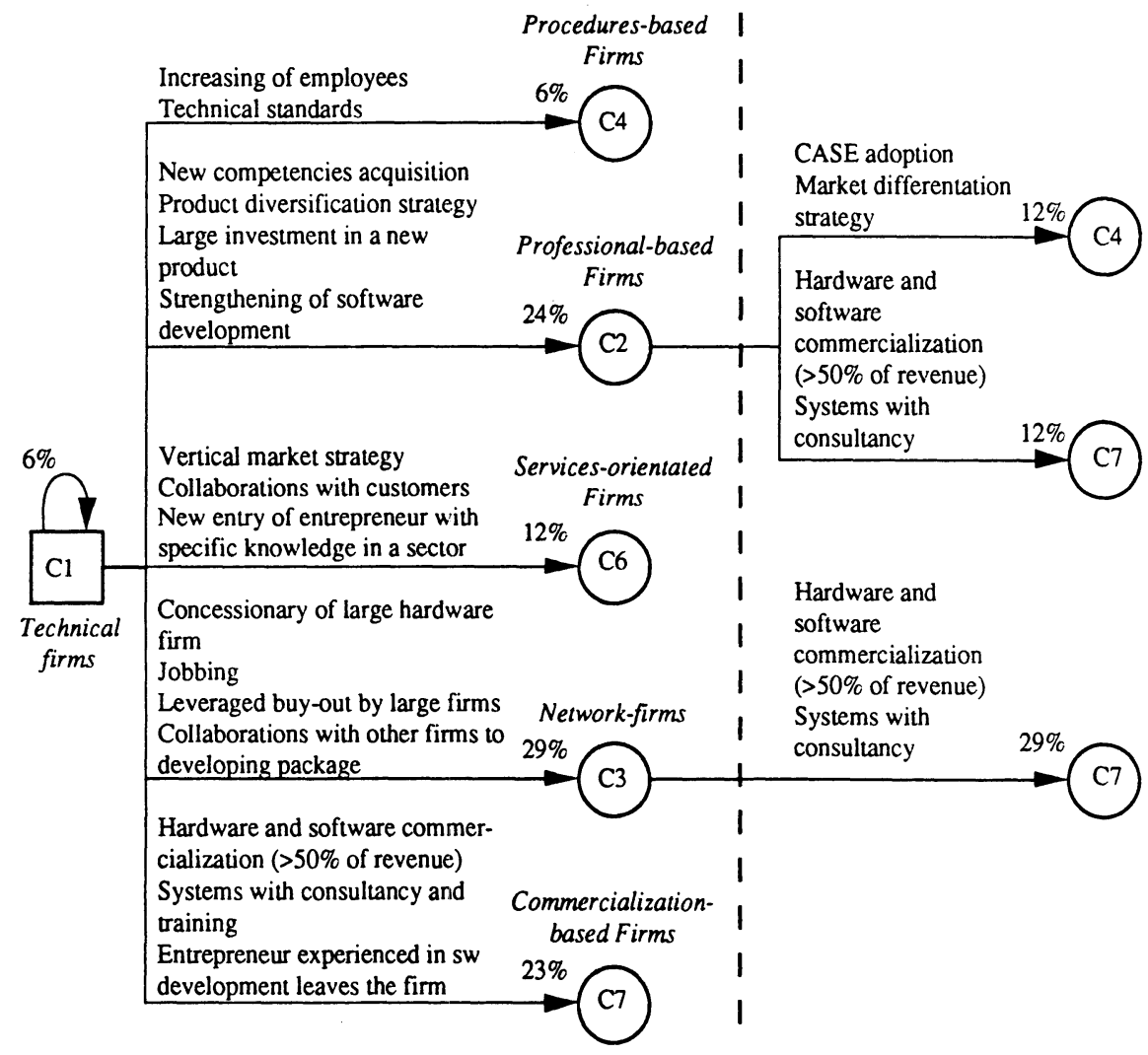

First organizational transformation

Second organizational transformation

Figure 1 Organizational transformations of technical-firms. 
Finally, the passage from $\mathrm{C} 1$ configuration (technical-firms) to $\mathrm{C} 7$ configuration (commercialization-orientated firms) is characterized by a commercialization strategy (hardware and software commercialization activities $>50 \%$ of revenue).

With reference to the part of the Figure 1 that shows the second organizational transformations, we have that the passage from $\mathrm{C} 2$ configuration (professional-based firms) to C4 configuration (procedures-based firms) is characterized by a market differentiation strategy and by an internalization strategy of technological resources (CASE adoption), while the passage from $\mathrm{C} 2$ configuration (professional-based firms) to $\mathrm{C} 7$ configuration (commercialization-orientated firms) and from C3 configuration (network-based firms) to C7 configuration (commercialization-orientated firms) are characterized by a commercialization strategy (hardware and software commercialization activities $>50 \%$ of revenue).

In conclusion, most transformations led the firms to reduce their involvement in software development. Only the development path from $\mathrm{C} 1$ (technical-firms) to $\mathrm{C} 2$ (professional-based firms) to C4 (procedures-based firms), regarding only $12 \%$ of the firms, led them to strengthen their software competencies. This path was supported by a strategy that allow the passage from an initial subset of resources, constituted by the entrepreneurial know-how, to a second subset of resources, constituted by a network of professionals, and at last, to a third subset of resources, constituted by internal and/or external technologies of software development and a more structured organization.

\subsection{The growth path based on market entrepreneurial know-how}

The firms originated from a configuration based on market entrepreneurial know-how (C5 configuration) have different growth paths:

i) most of those firms strongly reduces software development, giving rise to a variety of activities, within which software development is only a complementary activity. This fact determines the passage from C5 configuration (market-orientated firms) to C7 configuration (commercialization-based firms);

ii) some firms establish close collaborations with other firms (generally commercial collaborations). This fact determines the passage to C3 configuration (network-firms). The passage from C5 configuration (market-orientated firms) to C3 configuration (network-firms) and to $\mathrm{C} 7$ configuration (commercialization-based firms) can be occur directly, or through other intermediate configurations.

From a statistical point of view we can observe that the most important paths that the firms follow are those depicted in Figure 2.

We have that $20 \%$ of the firms starting with $\mathrm{C} 5$ configuration pass to the $\mathrm{C} 2$ configuration; and successively to $\mathrm{C} 7$ configuration (13\%) and to $\mathrm{C} 3$ configuration (7\%), while $35 \%$ of the firms starting with $\mathrm{C} 5$ configuration pass to $\mathrm{C} 3$ configuration and then to final $\mathrm{C} 7$ configuration (20\%). The others remain in C3 configuration (15\%) or pass strictly to C7 configuration (38\%); only one passes directly to $\mathrm{C} 4$ configuration (7\%). With reference to Figure 2, the passage from $\mathrm{C} 5$ configuration (market-orientated firms) to $\mathrm{C} 4$ configuration (procedures-based firms) is characterized by an internalization strategy of technological resources (CASE adoption) and of organizational resources (engagement of new employees), and by a market differentiation strategy. 


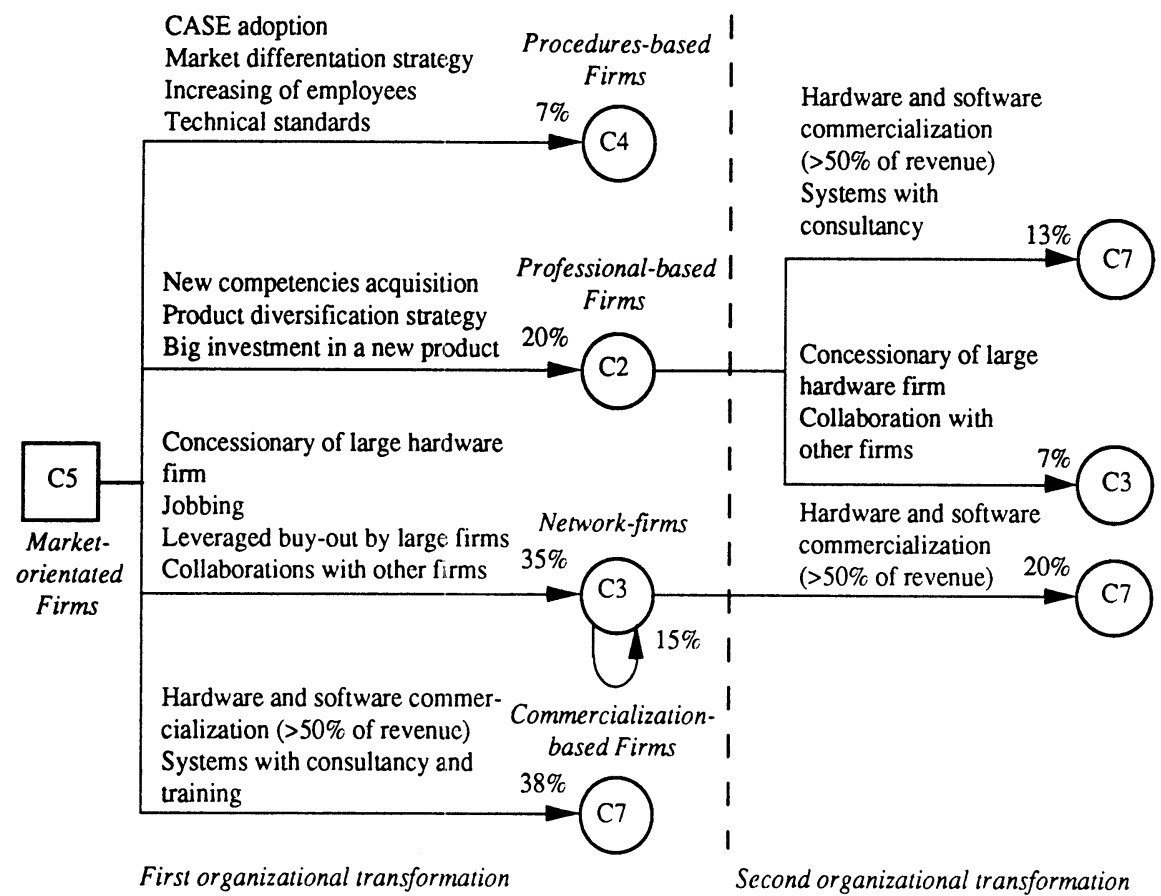

Figure 2 Organizational transformation of market-orientated firms.

The passage from C5 configuration (market-orientated firms) to C2 configuration (professional-based firms) determines an organizational transformation characterized mainly by a product diversification strategy and by a strategy of complex networking with professional resources (new technical competencies acquisition) with different degrees of membership in the firm., while the passage from C5 configuration (market-orientated firms) to $\mathrm{C} 3$ configuration (network-based firms) is characterized by a networking strategy (concessionaire of large hardware firm, jobbing, leveraged buy-out by large firms, collaborations with other firms).

Finally, the passage from $\mathrm{C} 5$ configuration (market-orientated firms) to $\mathrm{C} 7$ configuration (commercialization-orientated firms) is characterized by a commercialization strategy (hardware and software commercialization activities $>50 \%$ of revenue):

With reference to the part of the Figure 2 that shows the second organizational transformation, we say that the passage from $\mathrm{C} 2$ configuration (professional-based firms) to C3 configuration (network-based firms) is characterized by a networking strategy (concessionaire of large hardware firms, jobbing, collaborations with other firms), while the passage from $\mathrm{C} 2$ configuration (professional-based firms) to $\mathrm{C} 7$ configuration (commercialization-orientated firms) and from C3 configuration (network-based firms) to $\mathrm{C} 7$ configuration (commercialization-orientated firms) are characterized by a commercialization strategy. 
In conclusion, the development path of the market-orientated firms has some significant differences with the development path of the technical-firms. The most important aspect is that $\mathrm{C} 2$ configuration (professional-based firms) did not evolve towards a specialization in software production but it evolved towards hardware and software commercialization. Only 7\% of firms reached $\mathrm{C} 4$ configuration (procedures-based firms) through the internalization of technologies and methodologies, together with the hiring of new software employees.

\section{CONCLUSIONS}

At their very start firms have two possible configurations: firms based on technical entrepreneurial know-how, and firms based on market entrepreneurial know-how. Consequently, firms are polarized on the technology or on the market. The lack of initial configurations showing both competencies of market and technology is mainly due to the small size of the entrepreneurial group, usually one person who influenced the initial competencies of the firm.

Both those firms' groups have to complete their initial know how modifying the set of their resources. The firms with initial configuration based on technical entrepreneurial know-how have to complete their capability, expanding their market abilities. This occurs through different ways: i) collaborating with large firms; ii) collaborating with professionals and consultants; iii) using external competencies, both technical and market; iv) acquiring new market competencies through diversification of entrepreneurial group's activities, or through new market-oriented employees.

The firms with an initial configuration based on strong market entrepreneurial knowledge face several difficulties to complete their initial know how with technical competencies. Generally, those firms: i) reduce software development activity, diversifying towards services and hardware commercialization; ii) establish relationships with other firms.

The empirical evidences show that an important difference is present between the two firms' groups in the initial stages of their life. The firms with a strong technical know-how explore a wider set of possibilities than the firms of the other group, and their trajectory is more complex. Anyway, after few intermediate transformations, most of technical firms falls prevalently in the same configuration of the firms based on market competencies, that is they reach the configuration based on systems' commercialization (C7). This fact could be explained with the difficulty of both groups of firms to answer to the same competitive environment, which requires or a radical improvement of quality of products and services or to shrink the involvement in software development.

It is worthwhile to notify that few technical firms are able to realize this improvement (that is, to reach configuration (6), while this alternative appear more difficult to realize for firms based on market know-how. In any case the firms reaching this configuration develop a strong focus on a niche market.

In conclusion, it seems that most of firms are not able to sustain a competition mainly based on technological innovation, independently from their original know-how, and that the most important difference between the two groups is that the technical firms possess a set of resources that let them explore a wider set of possibilities than other firms. Most of the surveyed firms are forced to significantly reduce their involvement in software development and to shift their strategic focus to the commercialization and other information services. In 
other words, they stop to exist as software houses and as small software firms. For most of them their life as software producer lasted from three to seven years.

From the entrepreneurial point of view the knowledge of the configuration is important to understand the key resources sustaining the competition and the alternatives available to grow. From the public policy point of view, the knowledge of configurations and developmental trajectory provide information about the firms' specific weakness and help to define appropriate services supporting the competitiveness of the firm.

\section{NOTES AND ACKNOWLEDGMENTS}

Although the paper is based on a joint research between the three authors, of this version $\mathrm{M}$. Raffa and G. Zollo wrote $\S 1, \S 2, \S 3$ and $\S 4, R$. Caponi $\S 5, \S 6$ and $\S 7$. The research has been supported by CNR Strategic Project "Trasferimento delle tecnologie dei progetti finalizzati", and by MURST 60\% and 40\% $1992-1993$.

\section{REFERENCES}

Acs, Z.J. and Audretsch, D.B. (1990) The Economics of Small Firms. A European Challenge. Kluwer, Dordrecht.

Barocci, T.A., Wever, K.R. and Lahey, R.A. (1983) Human Resource Planning for Information Systems Personnel: Skills Mixes and Technological Trends, Working Paper 1478-83, MIT, Sloan School of Management.

Brandt, S. (1981) Strategic Planning in Emerging Companies. Addison Wesley, Reading (MA).

Churcill, N.C. and Lewis, V.L. (1983). The Five Stages of Small Firm Growth. Harvard Business Review, 63, 30-50.

Filion, L.J. (1991) Vision et relations: clefs du succès de l'entrepreneur. Les éditions de l'entrepreneur, Montréal.

Garden, A.M. (1992) Potential Reasons for Software Employees in Small Companies to Leave Their Present Company. IE'EE Trans. Eng. Manag., 39, 246-53.

Gibb, A. and Scott, M. (1985) Strategic Awareness, Personal Commitment and the Process of Planning in the Small Business. Journal of Management Studies, 22, (6).

Grant, R.M. (1991) The Resource-Based Theory of Competitive Advantage: Implications for Strategy Formulation. California Management Review, 33.

Greiner, L.E. (1972) Evolution and Revolution as Organizational Growth. Harvard Business Review, 50, July-Aug.

Huppert, R. (1981) Stratégies de développement des PMI françaises. Revue d'economie industrielle, 17.

Kao, J. (1991). The Entrepreneurial Organization. Prentice Hall, London.

Kay, N.M. (1984) The Emergent Firm. MacMillan, London.

Kelley, M.R. and Brooks, H. (1991) External Learning Opportunities and the Diffusion of Process Innovations to Small Firm. Technological Forecasting and Social Change, 39, (12). 
Kimberly, J.R. and Miles, R.H. (1980) The organizational life cycle. Jossey-Bass, San Francisco.

La Belle, C.D., Shaw, K. and Hellenack, L.J. (1980) Solving Turnover Problem. Datamation, April.

Lefebvre, E. and Lefebvre, L.A. (1992) Firm innovativeness and CEO characteristics in small manufacturing firms. Journal of Engineering and Technology Management, 9, 243-77.

Meyer, M.H. and Roberts, E.B. (1986) New Product Strategy in Small Technology-Based Firms: a Pilot Study. Management Science, 32, (7).

Meyer, A.D. and Goes, J.B. (1987) How organizations adopt and implement new technologies, in 47th Annual Meeting of the Academy of Management, New Orleans, LA.

Meyer, A.D., Tsui, A.S. and Hinings, C.R. (1993) Configurational Approaches to Organizational Analysis. Academy of Management Journal, 36, 1175-95.

Miller, D., Droge, C. and Toulose, J.M. (1988) Strategic process and content as mediators between organizational context and structure. Academy of Mangement Journal, 31, 544-69.

Miller, A.D. and Toulouse, J.M. (1986a,) Chief executive personality and corporate strategy and structure in small firms. Management Science, 32, 1389-409.

Miller, A.D. and Toulouse, J.M. (1986b.) Strategy, structure, CEO personality and performance in small firms. Am. J. Small Bus.. Winter, 47-62.

Mintzberg, H. (1985) Of Strategies, Deliberate and Emergent. Strategic Management Journal, 3.

Mintzberg, H. (1987) Crafting Strategies. Harvard Business Review, July-Aug.

OECD, (1982) Innovation in Small and Medium Firms. Paris.

OECD, (1986) Software: A New Industry. Paris.

Pavitt, K. (1988) The Size and Structure of British Technological Activities: What We Know and Do Not Know. Scientometrics, 14, 329-46.

Prahalad, C.K. and Hamel, G. (1990) The Core Competence of the Corporation. Harvard Business Review, 68, 79-91.

Quinn, J.B. (1979) Technological Innovation, Entrepreneurship and Strategy. Sloan Management Review, 20, (3).

Raffa, M. and Zollo, G. (1988) Software: tecnologia e mercato. Il Mulino, Bologna.

Raffa, M. and Zollo, G. (1994) The Role of Professionals in Small Italian Firms. Journal of Systems Software, 26, 19-30.

Reid, G.C. and Jacobsen, L.R. (1988) The Small Entrepreneurial Firm. Aberdeen University Press, Aberdeen.

Roberts, E.B. (1991) The technological base of the new enterprise. Research Policy, 29, 28398.

Rothwell, R. (1988) Small Firms, Innovation and Industrial Change. Small Business Economics, 1, (1).

Rothwell, R. and Zegveld, W. (1982) Innovation and the Small and Medium Sized Firm. Frances Pinter, London.

Storey, D.J. and Johnson, S. (1987) Job Generation and Labour Market Changes. MacMillan, London.

Weinberg, G.M. (1982) Understanding the Professional Manager. Little Brown, Boston.

Werner, F.L. (1983) Critical Issues in Software. Wiley, New York. 


\section{BIOGRAPHICAL NOTES}

Mario Raffa, graduated at the University of Naples "Federico II", is professor of Business Economics and Organization at the Faculty of Engineering of Naples. He is also the scientific director of ODISSEO, the Centre for organization and technological innovation, Department of Computer Science and Systems, University of Naples "Federico II". He has published in several journals and has presented papers at international conferences on innovation management, organization, small innovative firms and relationships between small and large firms. In 1991 he received the "Award of Excellence" in Vienna for the best contribution presented to the 36th ICSB World Conference. In the last years he carried out a research project on small innovative firms in Italy and other European countries.

Giuseppe Zollo, graduated at the University of Naples "Federico II", is an associate professor of Business Economics and Organization at the Faculty of Engineering of Naples. During the years 1985-86 he has been Visiting Research Associate at Dept. of Economics of Northeastern University, Boston, MA. At present, he is a coordinator of a research unit of CNR (National Research Committee). In 1992 he received the "Entrepreneurship Award" in Barcelona for the best contribution presented to the 6th EIASM Workshop "Research in Entrepreneurship".

Renata Caponi, graduated at the University of Naples "Federico II" in Electronic Engineering, is junior researcher for ODISSEO-DIS. She is also research fellow at University of Rome "Tor Vergata". In 1993 she has won a scholarship ATA (Associazione Tecnica dell'Automobile) on the management of human resources in the small innovative firms. At present she makes research activities on small innovative software firms. 